\title{
trabalnonecessário
}

issn: $1808-799 X$

ano 7 - número 9 - 2009

\section{O DILEMA DO TEMA EMPREGO NA EDUCAÇÃO DE JOVENS E ADULTOS: A ABORDAGEM DE MICHAEL APPLE E ANTONIO GRAMSCI FRENTE À IDEOLOGIA DO "AUTO-FLAGELO EMPREGATÍCIO".}

\author{
Alceu Júnior Paz da Silva \\ alqueno@gmail.com \\ Luiz Carlos Nascimento da Rosa \\ liscatupa@bol.com.br
}

\begin{abstract}
Resumo:
O cenário contemporâneo de desemprego massivo e de intensificação da precarização do trabalho tem levado para o interior dos cursos de Educação de Jovens e Adultos o imaginário de que a escolarização média é fundamental para a qualificação profissional e a conquista de (melhores) empregos. O objetivo deste trabalho é problematizar a construção curricular da EJA frente ao interesse destes jovens e adultos em se qualificarem para o mundo do trabalho. Para isso utilizamos a teoria do currículo de Michael Apple e as contribuições da Teoria Social Marxiana de Gramsci como instrumentos teórico-metodológicos a fim de investigarmos os aspectos hegemônicos nos quais o currículo está imerso.
\end{abstract}

Palavras-chave: Emprego; Educação de Jovens e Adultos; Ideologia.

\section{THE DILEMMA OF EMPLOYMENT THEME IN ADULT AND YOUTH EDUCATION: THE MICHAEL APPLE AND ANTONIO GRAMSCI'S APPROACH AGAINST TO THE SELF- SCOURGE'S IDEOLOGY}

\begin{abstract}
:
The contemporary setting of huge unemployment and precarization of work has brought to Adult and Youth Education courses an imaginary that secondary education is fundamental for professional qualification and achievement of (better) jobs. The objective of this work is to problematize the Curriculum's construction according to young and adults interests in order to qualify them to the world of work. For that purpose, we adopted Michael Apple's curriculum theory and some contributions of Gramsci's Marxist social theory as methodological and theoretical tools to investigate hegemonic aspects in which the curriculum is immersed.
\end{abstract}

Key words: Employment; Adult and Youth Education; Ideology. 


\section{frabalhonecessário \\ issn: $1808-799 \mathrm{X}$ \\ ano 7 - número 9 - 2009}

\section{O contexto da investigação: a ideologia na Educação de Jovens e Adultos}

Os cursos de Educação de Jovens e Adultos têm se caracterizado pela presença de alunos que, em sua maioria, desejam se capacitarem para a luta por (melhores) empregos dentro do excludente mercado de trabalho atual, fato que torna o tema emprego lugar comum para qualquer investigação curricular realmente atenta à vida cotidiana desses educandos.

Se, por um lado, a necessidade de capacitação sugere uma defasagem intelectualcultural das classes operárias em relação ao processo de trabalho, por outro, a falta de determinados tipos de conhecimentos, por esses grupos sociais, mostra a desigualdade com que os aportes culturais são acessados numa sociedade estratificada, remetendo a uma irregular distribuição do poder político e econômico no seio da vida social.

$\mathrm{Na}$ sociedade em geral se estabelece uma relação entre conhecimento e poder, sendo que, na Escola, a prática de seleção e organização dos conhecimentos escolares que serão distribuídos está sempre relacionada dentro de uma totalidade de possibilidades, para além de programas pré-determinados, parâmetros curriculares ou livros didáticos, constituindo-se, de tal forma, constituindo-se como um processo ideológico (latente ou explicito), uma vez que, a reflexão sobre o porquê de um determinado conhecimento dever ser ensinado e não outro está na base norteadora e teleológica da prática educativa.

As reflexões, no âmbito ideológico dos critérios de seleção dos conteúdos escolares, nos levam ao contexto de outro conceito fundamental para as discussões curriculares, 0 de hegemonia, resgatado por Michael Apple de Antonio Gramsci para melhor investigar as relações entre a reprodução cultural e a reprodução econômica.

Hegemonia é a forma como as sociedades ditas democráticas (as que não se organizam sob a forma de Ditaduras Militares explícitas), se mantêm "coesas" e, mesmo quando mergulhadas em contradições sociais como a miséria (cultural-econômica) de muitos e a riqueza de poucos, não têm sua estrutura econômica radicalmente alterada. É 


\title{
trabalhonecessário \\ issn: $1808-799 \mathrm{X}$ \\ ano 7 - número 9 - 2009
}

uma espécie de consenso passivo geral, difundido e exercido na sociedade no intuito de garantir conscientemente a legitimidade das contradições de classe existentes, impedindo a formação de um horizonte intelectual que as problematizem e promovam suas superações.

Dessa forma, a educação como momento de mediação, entre o ser humano, a cultura e o seu processo de desenvolvimento histórico, é um lócus de disputa pela hegemonia, o qual pode tanto contribuir com a conservação das atuais relações sociais, quanto pode conduzir a ações de caráter contra-hegemônico.

Nesse contexto, Apple enfatiza que

\begin{abstract}
a hegemonia é produzida e reproduzida pelo corpus formal do conhecimento escolar, assim como pelo ensino oculto[,] a tradição e incorporação seletivas atuam no conhecimento manifesto, de modo que alguns significados e práticas são escolhidos como importantes e outros são menosprezados, excluídos, diluídos ou reinterpretados (Apple, 1982, p. 125).
\end{abstract}

A crítica radical à legitimidade do conhecimento escolar atribuída por Apple nos levou a investigar os possíveis elementos ideológicos que podem estar atuando na seleção dos saberes escolares quando se têm como eixo temático o emprego. Com isso, materializada nas relações entre hegemonia e construção curricular, a questão que norteou nossa investigação é assim expressa: quais são os aspectos que têm influenciado a construção curricular da EJA quando se tem por base a realidade social de Jovens e Adultos e os seus anseios em relação ao mundo do trabalho?

No caminho investigativo percorrido, utilizamos um Diário de Bordo de pesquisa, de modo a coletar, sistematizar e refletir sobre as vivências docentes na disciplina de Química, no curso de EJA do Instituto Estadual de educação Olavo Bilac (Santa Maria/RS). Num primeiro momento, procuramos em Gramsci e Apple os pressupostos educacionais para Jovens e Adultos a partir de uma abordagem relacional entre Cultura e Trabalho para, em seguida, utilizá-los como instrumentos teórico-filosóficos no enfrentamento das relações entre o currículo da EJA e o tema trabalho e emprego.

Diante do ambiente curricular psicologizado, tentamos explorar as contribuições de Gramsci e Apple para uma construção curricular na EJA que supere a naturalização do 


\section{trabalhonecessário \\ issn: $1808-799 \mathrm{X}$ \\ ano 7 - número 9 - 2009}

real, processo no qual se situa, ganhando força e centralidade, as saídas individualistas para os fenômenos da qualificação para o trabalho e o desemprego promovidas por uma ideologia do "auto-flagelo" empregatício, inerente às práticas pedagógicas vivenciadas.

\section{Pressupostos educacionais para Jovens e Adultos: a dialética entre Cultura e Trabalho em Apple-Gramsci}

As vivências no curso de EJA, onde constatamos os anseios dos alunos em qualificarem-se para a aquisição de empregos, nos remeteram à reflexão sobre a natureza do processo educacional de forma a problematizar as relações entre a Educação e o mundo do trabalho.

Nossas discussões iniciais, junto ao coletivo de professores, assumiram duas perspectivas: a) A escola deve preparar os alunos jovens e adultos para o trabalho, isto é, assumir uma dimensão profissionalizante; b) A escola nada tem a ver com a profissionalização, devendo, assim, fundar-se na cultural geral, assumindo-se como escola de formação humanística.

É nesse contexto, que assumimos as reflexões de Gramsci sobre a escola diante deste impasse de relacionar o mundo do trabalho com o mundo da cultura. Para Gramsci (1978, p. 118), a revolução industrial ao transformar a vida no campo e na cidade, exigiu um novo tipo de formação intelectual, fato que provocou a crise da escola tradicional de cultura humanista e abriu espaço para a escola tecnicista ligada diretamente aos interesses da produção. Entretanto, sem menosprezar a relevância da formação cultural geral humanista e, menos ainda, dos processos produtivos modernos, a saída vislumbrada por Gramsci foi a de uma Escola Unitária, a qual deveria compreender essas duas dimensões (Trabalho-Cultura).

Cabe indagar, então: quais os fundamentos e as características dessa proposta unitária? Ao estudar a implementação do Fordismo na América (EUA), Gramsci (1989-b, p. 406-407) percebe que a necessidade da organização produtiva fordiana implica numa 


\section{frrabalhonecessário}

issn: $1808-799 \mathrm{X}$

ano 7 - número 9 - 2009

certa liberdade para os trabalhadores, pois não estariam submetidos apenas à coerção direta, e sim à coação combinada com altos salários. Neste contexto, evidenciava-se a possibilidade de os trabalhadores melhorarem de vida, isto é, "de alcançar[em] o nível de vida adequado aos novos modos de produção e de trabalho (Gramsci, 1989-b, p. 407)”.

Entrementes, no Fordismo, sob a égide capitalista, essa liberdade é logo objeto de coerção. O alto salário vinha juntamente com a necessidade de controle, por parte dos industriais, sobre o seu gasto "racional". Destacavam-se medidas de controle sobre a boemia, o uso de bebida alcoólica e o sexo, a fim de preservar, fora da fábrica, a integralidade do operário necessária ao processo de produção. Esse fato leva Gramsci a observar que "os novos métodos de trabalho estão indissoluvelmente ligados a um determinado modo de viver, de pensar e sentir a vida; não é possível obter êxito num campo se obter resultados tangíveis no outro (Gramsci, 1989-b, p. 396)”.

Essa compreensão da relação dialética entre trabalho e cultura é evidenciada por Gramsci ao afirmar que

[os] industriais norte-americanos compreenderam muito bem esta dialética inerente aos novos métodos industriais. Compreenderam que "gorila domesticado" é apenas uma frase, que o operário continua "infelizmente" homem e, inclusive, que ele, durante o trabalho, pensa demais ou, pelo menos, tem muito mais possibilidade de pensar, principalmente depois de ter superado a crise de adaptação. Ele não só pensa, mas o fato de que o trabalho não Ihe dá satisfações imediatas, quando compreende que se pretende transformá-lo num gorila domesticado, pode levá-lo a um curso de pensamentos pouco conformistas. A existência desta preocupação entre os industriais é comprovada por toda uma série de cautelas "educativas", que se encontram nos livros de Ford e de Philip (Gramsci, 1989-b, p. 404).

Com isso, constata-se que o processo de organização produtiva implica numa certa liberdade histórica ao trabalhador, a qual é imediatamente objeto de "preocupação" dos industriais, ou seja, necessidade e liberdade são dicotomizadas pelo capitalismo, então, cabe ao processo educativo e político implementar essa unidade.

Isso leva Gramsci a situar a luta pela liberdade (concreta) dentro da esfera produtiva (da necessidade), isto é, esperar que a liberdade dos trabalhadores se materialize com a superação futura das contradições capitalistas é idealismo utópico, pois isso é tarefa para o agora, para o presente. A liberdade deve ser pensada no seio da necessidade, e é 


\section{[trabalhonecessário}

issn: $1808-799 \mathrm{X}$

ano 7 - número 9 - 2009

vinculado a este projeto sócio-político que ele vai propor o trabalho como princípio pedagógico para a escola unitária.

Mas quais as características desta escola unitária? Em que consiste a assunção do trabalho como princípio educativo? A Escola Unitária (elementar e média) caracteriza-se pelo seu caráter "desinteressado", a qual é ulteriormente complementada pela Escola Profissionalizante, essa sim, "interessada".

O termo "desinteressado" diz respeito à escola de formação humanística, de cultural geral, sem fins imediatos e utilitaristas, ou seja, que não "interesse" a determinados estratos sociais, mas é um conjunto de saberes e valores relevante (que "interessa") para a humanidade em sua totalidade. Além disso, cabe dizer que essa formação cultural difere da cultura tradicional enciclopédica, como exorta Gramsci:

É preciso desacostumar-se e parar de conceber a cultura como saber enciclopédico, para a qual o homem é um recipiente a ser enchido e no qual devem ser depositados dados empíricos, fatos brutos, e desarticulados [...]. Esta forma de cultura é realmente prejudicial sobretudo para o proletariado [...]. Esta não é cultura, é pedanteria, não é inteligência, é intelecto; e contra ela com razão se deve reagir. A cultura é algo bem diferente. É organização, disciplina do próprio eu interior, é tomada de posse de sua própria personalidade, é conquistar uma consciência superior, através da qual consegue-se compreender seu próprio valor histórico, sua própria função na vida, seus direitos e seus deveres (Gramsci, apud Nosella, 2004, p. 44).

E essa cultura "desinteressada" tem na última fase da escola unitária, o Ensino Médio, a intencionalidade de “criar os valores fundamentais do 'humanismo', a autodisciplina intelectual e a autonomia moral necessárias para uma posterior especialização (Gramsci, 1978, p. 124)", quer seja na universidade, ou na esfera produtiva. Nessa fase, os elementos e métodos criativos das ciências, das artes, etc. deixam de ser privilégio da Universidade para serem estudados na escola, tornando-a uma escola "criadora", onde se tende a "expandir a personalidade, tornada autônoma e responsável, mas com uma consciência moral e social sólida e homogênea (Gramsci, 1978, p. 124)".

\section{Esta escola criadora}

não significa escola de "inventores e descobridores"; ela indica uma fase e um método de investigação e de conhecimento, e não um "programa" predeterminado que obrigue à inovação e à originalidade a todo custo. Indica que 


\section{trabalnonecessário}

issn: $1808-799 \mathrm{X}$

ano 7 - número 9 - 2009

a aprendizagem ocorre notadamente graças a um esforço espontâneo e autônomo do discente, e no qual o professor exerce apenas uma função de guia amigável...(Gramsci, 1978, p. 124).

Mas a escola unitária, de cultura "desinteressada", participativa e criativa se articula sobre o trabalho como princípio educativo. Em que consiste isso? Escola de cultura "desinteressada" não significa escola neutra ideologicamente, significa que a sua unitariedade está no fato de que o trabalho industrial moderno, a sociedade industrial moderna, é a sua fonte de inspiração.

A escola unitária deve buscar "fora dela", na prática social dos alunos, em suas vivências coletivas e individuais na sociedade moderna, os elementos que a complementam. A prática educativa escolar ao ligar-se à realidade concreta, ao trabalho industrial moderno, busca superar as práticas enciclopedistas, pois os conhecimentos não são abordados de forma abstrata, mas, ao contrário, são relacionados com a realidade cotidiana. É com a apreensão do conhecimento (cultura) elaborado que a realidade prática dos jovens e adultos se mostra mais "rica". A questão essencial é a busca pela unitariedade, a ligação orgânica, entre escola e sociedade (o mundo industrial moderno).

Assim, Escola "desinteressada" não se pretende neutra, pois intenciona, por meio da cultura, ensinar a "enfrentar" o mundo do trabalho. Não é construindo no seio escolar uma pequena empresa ou uma cooperativa, mas é trazendo para a escola os conflitos e os processos que marcam a natureza do trabalho humano contemporâneo, a fim de problematizá-los, criticá-los por meio da História e da Política.

Embora sob o regime social capitalista o trabalho apresente-se como objeto de exploração que reduz grande parte da população ao reino da necessidade, para Gramsci o trabalho, como princípio educativo, deve ser apreendido como momento histórico imediato de luta pela liberdade. Daí que

a tendência democrática, intrinsecamente, não pode consistir apenas em que um operário manual se torne qualificado, mas em cada cidadão possa se tornar governante e que a sociedade o coloque, ainda que abstratamente, nas condições gerais de poder fazê-lo: a democracia política tende a fazer coincidir governantes e governados (no sentido de governo com o consentimento dos governados), assegurando a cada governado a aprendizagem gratuita das capacidades e da preparação técnica geral necessárias ao fim de governar (Gramsci, 1978-a, p. 137- grifos do autor). 


\section{frabalhonecessário \\ issn: $1808-799 \mathrm{X}$ \\ ano 7 - número 9 - 2009}

Assim, a cultura "dessinterada" da escola unitária, intenciona a formação do ser humano onilateral, que, por meio da Ciência, da Arte, da Literatura, aborde valores éticoculturais necessários para que os educandos se tornem ativos-criativos e qualifiquem suas práticas sociais, e, dessa forma, em condições "culturais" de "governar" enfrentem de forma crítica os desafios do mundo do trabalho.

\section{Problematizando o currículo da EJA frente ao tema trabalho e emprego}

A assunção do trabalho e emprego como elemento norteador da construção curricular para a EJA, além de corresponder aos anseios concretos dos alunos, evidencia uma totalidade de contradições sócio-econômicas e culturais. No capitalismo contemporâneo, a incorporação de inovações tecnológicas e de novas formas de organização e gerenciamento no processo de trabalho têm se voltado para a intensificação e a precarização do trabalho, à medida que exclui diretamente da esfera produtiva uma grande quantidade seres humanos, gera em níveis alarmantes, uma multidão de desempregados.

Diante desse limite estrutural imposto pelo capitalismo, que impede a manutenção objetiva da dignidade humana ao decretar o destino de uma multidão de jovens e adultos à exploração do trabalho ou a miserabilidade, se insere a educação. A nossa prática social educativa na EJA nos mostra que, longe de ser elucubração intelectual de algum filósofo desocupado, o tema trabalho e emprego emerge como um "problema concreto" do currículo.

É com base nisso que nos deparamos com a seguinte questão: A escola, ao trazer para o currículo as questões sobre o mundo do trabalho, deve ajudar os alunos a se capacitarem para o enfrentamento do desemprego e/ou para a aquisição de melhores empregos?

No caminho para a reflexão sobre essa questão encontram-se as relações entre educação e trabalho, que, assim como o próprio processo de produção capitalista, 


\section{frabalhonecessário \\ issn: $1808-799 \mathrm{X}$ \\ ano 7 - número 9 - 2009}

sofreram transformações nos últimos tempos. Inicialmente, a chamada teoria do capital humano expressava a relação educação-trabalho no sentido de que a escola atuasse como uma "entidade integradora (Gentili, 2005, p. 48)", de suma importância para o desenvolvimento econômico.

Essa função "integradora” é descrita por Gentili:

A promessa integradora da escolaridade estava fundada na necessidade de definir um conjunto de estratégias orientadas para criar as condições "educacionais" de um mercado de trabalho em expansão e na confiança (aparentemente incontestável) na possibilidade de atingir e pleno emprego. A escola se constituía, assim, num espaço institucional que contribuía para a integração econômica da sociedade formando o contingente (sempre em aumento) da força de trabalho que se incorporaria gradualmente ao mercado (Gentili, 2002, p. 49-50).

A ênfase nessa abordagem integradora da escola dava-se no ambiente do póssegunda guerra, onde o Estado do bem-estar social promovido pelos governos socialdemocratas europeus atingiram um nível de crescimento econômico elevado, combinado com uma igual política de geração de empregos, aumento dos salários e diminuição da pobreza. Pois as fagulhas mal apagadas do pós-guerra poderiam motivar a ascensão operária em sua luta pelo poder político, assim, o dique de contensão social-democrata evitaria por meio do quase pleno emprego qualquer tentativa de transformação revolucionária das sociedades capitalistas industrializadas.

Mas uma transformação substancial na teoria do capital humano veio inicialmente com a crise do capitalismo dos anos 70, onde, segundo Prieb (2005, p. 25-26) os produtos alemães e japoneses aumentaram a concorrência intercapitalista devido aos seus baixos custos de produção, fato que diminuiu a taxa de lucro dos capitalistas norteamericanos, a medida que afetou também o Japão e a Alemanha ao impulsionar a sobrevalorização das suas respectivas moedas.

Esse fato abre as portas para uma reestruturação do capitalismo internacional, a fim de amenizar suas contradições internas na busca pela manutenção de maiores taxas de lucro, a qual se materializou na maximização da exploração dos trabalhadores, no prolongamento da jornada de trabalho, na precarização do trabalho e na redução do número de trabalhadores no processo de produção impulsionados pela aplicação das 


\section{frabalinanecessário \\ issn: 1808-799X \\ ano 7 - número 9 - 2009}

inovações tecnológicas e das novas formas de organização do trabalho, em especial o Toyotismo.

É nesse período que Gentili evidencia uma mudança substancial na teoria do capital humano, na sua forma de conceber a relação educação-trabalho, por meio da "desintegração" da promessa da escola como um agente integrador.

...é importante destacar que a desintegração da promessa integradora não tem
suposto a negação da contribuição econômica da escolaridade, mas sim uma
transformação substantiva de sentido. Passou-se de uma lógica da integração em
função de necessidades e demandas de caráter coletivo (a economia nacional, a
competitividade das empresas, a riqueza nacional, etc.) para uma lógica
econômica estritamente privada e guiada pela ênfase nas capacidades e
competências que cada pessoa deve adquirir no mercado educacional para
atingir uma melhor posição no mercado de trabalho (Gentili, 2002, p. 51- grifo
nosso).

Juntamente como a derrocada do pleno emprego ocorre um deslocamento da função econômica da escolaridade, agora cabe ao indivíduo a responsabilidade de capacitar-se por si mesmo, na luta por um lugar no mercado de trabalho, e o que a escolaridade oferece-Ihe é apenas uma "promessa de empregabilidade (Gentili, 2002, p. 51)".

Mas são nos tempos atuais que o discurso sobre a empregabilidade vem tomando destaque sob a perspectiva neoliberal de competitividade, produtividade e eficiência. $A$ tarefa individual de capacitação para a disputa de vagas no mercado de trabalho "acaba" (ou melhor, "mascara") com a responsabilidade do Estado e das empresas de garantir empregos, pois agora isto é incumbência do ser e de suas capacidades individuais.

O desprezo do capitalismo contemporâneo pela força de trabalho no processo de produção vem corroborar com a desmistificação da correspondência direta e mecânica entre educação e desenvolvimento econômico. Pois, se por um lado a capacitação mediante a apreensão de competências e habilidades proporcionam que $\mathrm{o}$ indivíduo dispute as vagas de trabalho ofertadas pelo mercado, por outro o desenvolvimento econômico independe do aumento do número de trabalhadores no processo de produção, como afirma Gentili "as economias podem crescer e conviver com uma elevada taxa de desemprego e com imensos setores da população fora dos benefícios do crescimento econômico (Gentili, 2002, p. 54)". 


\title{
frabalhonecessário \\ issn: $1808-799 \mathrm{X}$ \\ ano 7 - número 9 - 2009
}

O que o referido autor evidencia, podemos relacionar com o "processo de produção destrutiva" que possibilita ao capitalismo equilibrar a relação dialética entre produção e consumo, uma vez que, a grande maioria da população encontra-se empobrecida, a capacidade de consumo de mercadorias pela sociedade é drasticamente diminuída, o que provocaria uma crise capitalista. Entretanto, a sapiência diabólica capitalista promove uma saída. Efetiva-se a diminuição da vida útil dos produtos a fim de aumentar a rapidez do consumo, onde, assim, o consumismo exacerbado de poucos promove a miserabilidade de muitos.

Esse processo de produção destrutiva denominado por Mészáros é assim caracterizado:

\begin{abstract}
... O capitalismo corresponde a uma sociedade descartável. O equilíbrio entre a produção e consumo só se concretiza quando ocorre o aumento da velocidade do consumo, ou seja, o descarte prematuro de grandes quantidades de mercadorias que anteriormente pertenciam à categoria de bens duráveis, devendo os mesmos serem descartados antes de esgotar sua vida útil. [...] Logo, quando uma nova tecnologia é criada, é decretada sua morte. O desenvolvimento dos meios de produção se opõe às necessidades humanas, pois o que importa é a expansão do capital (Mészáros apud Lucena, 2005, p. 192).
\end{abstract}

Como podemos ver, a reestruturação capitalista, seja qual for, não perde sua incessante intenção de acumular capital à medida que promove o acúmulo de miséria e desemprego. Recentemente, a OIT (2006) confirma que um terço da mão-de-obra disponível mundialmente está em condições de desemprego ou subemprego, desses 180 milhões em condição de desemprego aberto.

O que queremos evidenciar é que as transformações ocorridas no capitalismo nos últimos tempos definitivamente não nos levam a conceber a escolaridade como elemento fulcral para a aquisição de empregos, o capitalismo em sua base estrutural possui o germe promotor do desemprego.

É por esse motivo estrutural que o discurso da empregabilidade, em nosso entender, vai ocupar um papel central na manutenção da exclusão da grande maioria da população ao direito de emprego. Se num primeiro momento, vivenciamos no ambiente escolar uma certa "ideologia da qualificação" (pela promessa de empregabilidade), num segundo, a 


\section{traoalhonecessário \\ issn: $1808-799 \mathrm{X}$ \\ ano 7 - número 9 - 2009}

tendência dos discursos correntes vem materializando uma espécie de "auto-flagelo empregatício".

O autoflagelo empregatício se manifesta quando se torna senso comum, para o indivíduo: que ele é o único responsável pelo seu sucesso na obtenção de um emprego; que o Estado não tem incumbência (ou é incapaz) de promover políticas públicas que gerem empregos; que as suas competências e habilidades são sempre determinantes na obtenção (ou não) de um emprego; que a inevitável utilização de tecnologias é a responsável natural pela diminuição do número de empregos, enfim qualquer concepção que o torne psicologicamente promotor de seu, eventual, "fracasso" perante a busca (ou a manutenção) de empregos no mercado de trabalho.

De modo geral, a saturação ideológica do "auto-flagelo empregatício", ao individualizar, psiquicamente, o problema do emprego para o trabalhador, tende, na prática, a impedir as saídas coletivas, onde a conscientização-organização social ou sindical é substituída por uma "antropofagia interproletária".

Mas essa condição de ser não surge apenas de uma postura pueril em relação à realidade, pois, cotidianamente, os mais diversos meios de comunicação e informação, sustentam de forma tácita ou manifesta as visões de mundo "auto-flagelantes". Se tomarmos, por exemplo, jornais correntes, não faltam artigos evidenciando que para se conseguir um emprego: é preciso montar um bom currículo; que é fundamental saber se comportar na hora das entrevistas; que é preciso estar atento às diversas oportunidades que os setores "do momento" estão ofertando, como o empregado deve se relacionar com os chefes superiores; etc.

Citamos alguns exemplos encontrados nos respectivos artigos publicados no caderno Empregos e Oportunidades do jornal Zero Hora: "Quais são suas competências? Além de dominar técnicas específicas que cada função exige, profissionais também são recrutados pelas qualidades pessoais que possuem (Melo, 2006-a, p. 03)"; "Conflitos no escritório: perder o controle no local de trabalho, brigar com colegas e tornar o ambiente pesado pode prejudicar tanto o próprio profissional quanto o andamento de projetos na empresa (Melo, 2006-b, p. 03)" e "Ler faz diferença no mercado de trabalho: profissionais 


\section{frabalhonecessário \\ issn: $1808-799 \mathrm{X}$ \\ ano 7 - número 9 - 2009}

que falam bem e cometem poucos erros ao escrever têm mais chances de conquistar uma vaga (Santi, 2006, p. 03)".

Ainda, neste Caderno, evidenciamos um "esclarecedor" teste prático que, baseado num questionário e numa legenda de resultados, contendo a soma de acertos, Ihe permite avaliar o "seu" nível de empregabilidade, desde que você "[r]esponda a alternativa que melhor se adapta a suas atitudes do dia-a-dia. Seja sincero, pois a veracidade das respostas depende o resultado fiel do teste, elaborado pela psicóloga Simoni Missel (Zero Hora, 2006, p. 03)".

Ao mostrarmos essas formas sutis(?) de ideologização dos meios de comunicação em favor dos interesses do capital, não estamos dizendo que o trabalhador não deva lutar pela manutenção-obtenção dos empregos, mas, no entanto, estes fatores, como vimos analisando, por si só não explicam as "causas" do alto nível de desemprego.

Fica-nos mais clara a densidade desse viés ideológico, quando a análise do processo de qualificação dos trabalhadores, por meio, das investigações de Lucena (2005), nos mostra as ideologias e as contradições nas quais a formação dos trabalhadores está imersa.

Quando trazemos esse debate acerca da "influência ideológica" sobre a prática social de jovens e adultos, compreendemos que o capitalismo, além de aprisionar os trabalhadores de forma objetiva, ou seja, por meio da estrutura econômica que os condicionam ao cenário escatológico da precarização do trabalho e do desemprego, precisa promover, juntamente com o controle objetivo, um modo de mantê-los culturalmente sob controle. Em termos da dialética materialista, diríamos que para uma determinada conformação infraestrutural existe uma superestrutural, as quais permanecem, uma em relação à outra, em constante estado de dialetização.

$\mathrm{Na}$ acepção gramsciana é a hegemonia que "unifica dialeticamente" essas duas dimensões, ou seja, a base econômica com o consentimento (ideológico-cultural) geral, o qual permite que sejam manuteníveis as relações sociais de produção de uma época.

Essa "unificação" cultural exercida pela hegemonia é descrita por Gruppi: 


\section{frabalhonecessário}

issn: $1808-799 \mathrm{X}$

ano 7 - número 9 - 2009

A ideologia é o que mantém coeso o "bloco histórico" [estrutura econômica e o Estado], que solda entre si seus elementos, que permite manter unidas classes sociais diferentes e com interesses até opostos, antagônicos. A ideologia é o grande cimento de todo bloco histórico, faz parte de sua edificação. Esta não é só ideológica, mas cultural também, em primeiro lugar é política, mas não pode ser separada do aspecto da ideologia e das idéias (Gruppi, 1986, p. 82).

Dessa forma, a Hegemonia, como influência ideológico-cultural, viabiliza a continuação das relações de produção capitalismo no plano subjetivo geral. Embora, a atividade Hegemônica se processe de forma concreta, ela não se dá de forma plena e mecânica, pois sua execução está imersa em contradições e conflitos, que já constituem elementos para uma oposição contra-hegemônica.

O que nos cabe, como contestação dessa hegemonia, é o não alinhamento como as posturas ideológicas que naturalizam a atual condição social de miséria e desemprego. As "soluções" para esse problema se convertem em hegemonia capitalista quando se propagam que as saídas são "puramente individuais", e a luta entre os indivíduos (trabalhador, desempregado e capitalista) é da própria "essência do ser humano", ou seja, os melhores vencem! Conseguem empregos e pronto! Pois os melhores possuem "espírito empreendedor, criatividade, otimismo, perseverança, autoconfiança, disposição para o trabalho, domínio de técnicas atuais [e crêem] que a sociedade só pode progredir se forem respeitadas as leis do mercado (Duarte, 2001, p. 140)".

Segundo Duarte, com isso surge "a concepção de que o desenvolvimento tanto do gênero humano quanto de cada indivíduo é fruto dessa constante tensão entre individualismo e convivência social (Duarte, 2001, p. 137)". O que é aspecto central do capitalismo é "universalizado, no plano ideológico, a toda história humana, transformando a competição própria da sociedade mercantil em algo natural do ser humano em toda e qualquer época (Duarte, 2001, p. 137)”.

Este processo de naturalização

significa a tentativa de justificação, por meio da eternização e da universalização, de uma determinada realidade, apresentando-se como correspondente à natureza humana. A naturalização [é] a consideração como natural, isto é, como pressuposto da vida social, daquilo que é histórico, produto do desenrolar histórico das relações sociais (Duarte, 2001, p. 138). 


\section{Irrabalhonecessário}

issn: $1808-799 \mathrm{X}$

ano 7 - número 9 - 2009

Dessa forma, os fenômenos sociais, como o desemprego, aparecem como se fossem produzidos por leis naturais e alheias à condição humana. Em outras palavras, o desemprego assume aspecto metafísico ao serem ocultadas as contradições e as relações sociais que o criam, tornando senso comum a impossibilidade de uma atuação social na superação do desemprego. Como vimos anteriormente, tanto a aplicação da tecnologia e das formas de organização no processo de trabalho com o intuito de aumentar a exploração do trabalhador e da promoção da miséria, é fruto de decisões e juízos humanos, longe de ser uma "tendência natural".

É diante desse processo de disputa pela hegemonia social na sociedade capitalista que a escola se encontra, ou seja, imersa sob contradições e influência ideológica. Dessa forma, a escola pode servir como lócus de reprodução ideológica, ao materializar, na prática, perspectivas que naturalizam a as contradições sociais inerentes ao capitalismo contemporâneo. Um exemplo concreto foi constatado no conteúdo de um texto oferecido em nossas reuniões de planejamento curricular da EJA.

Nessa ocasião, e realidade específica, o seguinte relato foi produzido:

[...] e o que posso sentir é que existe um terreno de disputa ideológica e que a hegemonia capitalista tem tido sucesso. Digo isso, também, baseado no texto sobre o dia $1^{\text {a }}$ de maio, dia do trabalho, que foi oferecido para subsidiar nosso trabalho pedagógico. Seu título é: Os melhores vencem (Jornal Diário de Santa Maria, 01/05/2006). Novamente este texto limita a abordagem do mundo do trabalho à formação de habilidades e não está para além disto. $O$ texto desse jornal deu a martelada final para pregar no currículo a formação de habilidades, pois as habilidades não eram invenções nossas, eram requeridas pelo mundo do trabalho e o jornal confirmava isso (Diário de Bordo, 03/05/2006).

O referido texto (Os melhores vencem...) fazia alusão à necessidade de formar trabalhadores competentes a fim de proporcionar-lhes melhores chances de obtenção de empregos. A abordagem desse texto de jornal nos faz questionar a relação do currículo e estas "exigências do mercado de trabalho".

A escola no contexto da EJA deve assumir curricularmente a tarefa de formar habilidades e competências? Ao "contribuir" para a capacitação dos indivíduos, não estaria corroborando com a exploração do trabalho, ao baratear a força de trabalho para o capital? Não estaria aumentando os lucros capitalistas, ao livrar o capital da responsabilidade de custear a qualificação da força de trabalho, e conseqüentemente 


\section{frrabalnonecessário \\ issn: $1808-799 \mathrm{X}$ \\ ano 7 - número 9 - 2009}

agravando a correspondente acumulação de miséria? Diante da impossibilidade estrutural do capitalismo de gerar empregos, devido sua tendência em reduzir a parte variável do capital, a escola ao optar por formar competências, não estaria propagando falsos otimismos e servindo como tranqüilizante ideológico para jovens e adultos?

Em relação às questões de qualificação para o trabalho, as transformações ocorridas no âmbito da organização produtiva dialeticamente influenciaram as pedagogias e as formas de organização curricular. O movimento histórico que percorremos pela economia política agora será relacionado com as tendências curriculares correspondentes.

No período pré-crise capitalista dos anos 70, a supremacia na organização da produção era o modelo baseado no taylorismo-fordismo, e como vimos, é um modelo rígido, de produção massiva de um tipo de mercadoria e pouca flexibilidade em moldar a oferta a variações específicas de demanda. Este modelo apresentava-se "com tecnologia estável e com processos de base eletromecânica rigidamente organizados, que não abriam espaços significativos para mudanças, participação ou criatividade para a maioria dos trabalhadores (Kuenzer, 2002, p. 83)".

É nesse contexto, que se evidencia o modelo de currículo escolar forjado por uma visão positivista da ciência, a qual sugere uma estrutura rígida, fragmentada e baseada em objetivos técnicos de desempenho escolar.

Segundo Kuenzer estas propostas curriculares

organizavam rigidamente os conteúdos, em termos de seqüenciamento intra e extradisciplinares, os quais eram repetidos, ano após ano, por meio do método expositivo, combinado com cópias e questionários; a habilidade cognitiva a ser desenvolvida era a memorização, articulada ao disciplinamento, ambos fundamentais para a participação no trabalho e na vida social organizada sob a hegemonia do taylorismo-fordismo (Kuenzer, 2002, p. 84).

Uma vez que a atividade de trabalho consistia basicamente em movimentos mecânicos-repetitivos, a capacidade ou o treinamento de memorização já era o suficiente para o enfrentamento das tarefas padronizadas na fábrica.

Entretanto, a crise do capitalismo imediatamente coloca as condições para a sua renovação e reestruturação por meio de transformações nas formas organizativas de 


\section{frabalhonecessário \\ issn: $1808-799 \mathrm{X}$ \\ ano 7 - número 9 - 2009}

produção. O esgotamento do modelo taylorista-fordista convive com o surgimento do toyotismo.

Marcado pela flexibilidade de acumulação de capital, esse modelo exige ao trabalhador uma igual "flexibilidade" operacional nas atividades laborais, pois se caracteriza por ser um trabalhador multiuso, capaz de cumprir diferentes tarefas e operações na célula de produção. Ao contrário do modelo anterior, este além de fugir a rigidez procedimental daquele, ainda é acompanhado por mudanças radicais de base tecnológica.

A aplicações de novas tecnologias ao processo produtivo implica que o trabalhador detenha novos conhecimentos e habilidades. Segundo Kuenzer, essa nova forma produtiva vai exigir o desenvolvimento de habilidades cognitivas e comportamentais, tais como:

análise, síntese, estabelecimento de relações, rapidez de respostas e criatividade, diante de situações desconhecidas, comunicação clara de precisa, interpretação e uso de diferentes formas de linguagem, capacidade para trabalhar em grupo, gerenciar processos, eleger prioridades, criticar respostas, avaliar procedimentos, resistir a pressões, enfrentar mudanças permanentes, aliar raciocínio lógico-formal à intuição criadora, estudar continuamente... (Kuenzer, 2002, p. 86).

A exigência de tais habilidades vai se materializar na escola com a chamada "pedagogia toyotista (Kuenzer, 2002)", a qual se manifesta sob a concepção educacional de formação de competências. Mesmo que aqui não esgotemos a discussão sobre "o que são competências", tomamos como referencial a concepção que "chega" na escola, geralmente por meio dos Parâmetros Curriculares Nacionais - PCN's (Brasil, 2002).

O seguinte fragmento textual foi utilizado nas reuniões para ajudar a clarear as idéias coletivas de nós professores sobre o que se entende por competência. Vejamos:

Quando uma pessoa começa a aprender a dirigir, parece-lhe quase impossível controlar tudo ao mesmo tempo: o acelerador, a direção, o câmbio e a embreagem, o carro da frente, a guia, os espelhos (Meu Deus, 3 espelhos!! Mas eu não tenho que olhar para frente??). Depois de algum tempo, tudo isso lhe sai tão naturalmente que ainda é capaz de falar com o passageiro ao lado, tomar conta do filho no banco traseiro e, infringindo as regras de trânsito, comer um sanduíche. Adquiriu esquemas que Ihe permitiram, de certo modo, automatizar as suas atividades. Por outro lado, as situações que lhe apresentam no trânsito nunca são iguais. A cada momento terá que enfrentar situações novas e algumas 


\section{trabalhonecessário}

issn: $1808-799 \mathrm{X}$

ano 7 - número 9 - 2009

delas podem ser extremamente complexas [...] A competência implica uma mobilização dos conhecimentos e esquemas que se possui para desenvolver respostas inéditas, criativas, eficazes para problemas novos (Diário de bordo, 16/09/2005 grifos nossos).

Nesse texto fica claro o reducionismo psicológico do enfrentamento da construção curricular na escola. Aqui, competência é a mobilização de diferentes habilidades para a resolução de problemas cotidianos, é a apreensão de um método que condiciona o jovem e o adulto a estarem em constante processo de automatizarem suas atividades. A centralidade com que a formação de competências se estabelece em relação a centralidade do próprio conhecimento a ser ensinado, também, é vivenciado intensamente na escola, fato que favorece a idéia de que competência é um "método", que apreendido propicia a educação permanente dos jovens e adultos, como sugere o lema "aprender a aprender", incorporado aos PCN para EJA e na escola adotado como paradigma (Brasil, 2002, p. 19).

Nesse processo especifico de construção curricular, que por princípio segue as especificações dos PCN para a EJA, as habilidades que o currículo se propõe a desenvolver, e que definitivamente são as finalidades do processo pedagógico em sala de aula, foram assim estabelecidas:

1. Dominar a leitura, a escrita e as diversas linguagens; 2. resolver situaçõesproblema, selecionando, organizando e interpretando dados; 3 . organizar informações e conhecimentos disponíveis em situações concretas; 4. posicionarse criticamente; 5. planejar, trabalhar e decidir em grupo; 6 . conviver e interagir solidariamente; e 7 . comprometer-se com assiduidade e responsabilidade na execução e entrega de trabalhos (Diário de Bordo, 03/05/2006).

Comparadas essas habilidades curriculares com as requeridas pelo toyotismo, vislumbram-se claramente certas semelhanças como: capacidade de resolver situaçõesproblema (típico do trabalhador multitarefa?); saber trabalhar em grupo (na célula de produção?); posicionar-se criticamente (frente ao mundo do trabalho e suas contradições ou as situações cotidianas de trabalho?); conviver e interagir solidariamente (no local de trabalho, para aumentar a eficiência da empresa?); dominar a leitura e a escrita; selecionar, organizar e interpretar dados (qualificação indispensável para o uso das novas tecnologias no trabalho?); etc. 


\section{trabalnonecessário \\ issn: $1808-799 \mathrm{X}$ \\ ano 7 - número 9 - 2009}

Definitivamente, podemos vivenciar na prática que a construção curricular da EJA se dá pela adoção dos pressupostos contidos nos PCN para a EJA, e com eles a materialização, pelo menos em ato, das exigências toyotistas, limitando o aprofundamento da discussão política-ideológica acerca das relações entre educação e trabalho. Fato que de forma geral constitui o currículo como uma força produtiva a favor do capital e com isso, com as devidas ressalvas, agente de reprodução da hegemonia.

Enfim, o que abordamos até o momento nos leva a concluir que o trabalho é ainda o principal responsável de produção de riqueza capitalista, entretanto a utilização de novas tecnologias e formas de organização no processo de produção, com o intuito de maximizar a acumulação de capital, aumentou a intensificação e a precarização do trabalho gerando desemprego e miserabilidade a níveis inauditos. Esse processo implica que a assunção da "empregabilidade" como fundamento curricular não passa de tranqüilizante ideológico devido à própria escolaridade não ser um elemento fulcral para a aquisição de empregos, pois isso diz respeito à estrutura capitalista.

Além disso, o currículo organizado por meio da formação de competências antes mesmo de ter ineficácia formativa para geração de empregos, é ineficaz em relação ao próprio desenvolvimento capitalista que varia de região em região com exigências formativas diferenciadas (nem sempre as toyotistas). Mas no que essa pedagogia toyotista pode obter sucesso é no seu papel em psicologizar a abordagem curricular na escola, esvaziar as discussões políticas, ideológicas, históricas e sociológicas em relação ao tema "trabalho e emprego", à medida que contribui para omitir as contradições existentes no próprio capitalismo e nas relações entre escola e trabalho.

Dessa forma, acreditamos que a construção curricular está imersa num ambiente de disputa pela hegemonia, repleto de contradições e conflitos (veja apêndice A) e a assunção de uma postura crítico-ideológica em relação ao currículo deve estar concatenada com a perspectiva da superação das contradições entre capital e trabalho, à medida que assuma um caráter eminentemente contra-hegemônico ao colocar na ordem dia à necessidade da formação de um novo momento ético-politico, de uma nova cultura em oposição à dominada pela lógica capitalista contemporânea. 


\section{Gramsci, Apple e suas contribuições para o currículo de Química na EJA: naturalização $X$ historicização do real}

Nossa investigação vivenciou a dimensão hegemonista na qual o currículo com ênfase na formação de competências vem se materializando, pelo menos na escola, pois esvazia a discussão política, instrumentaliza "pedagogias de auto-ajuda", corrobora para a pacificação e a socialização de posturas "auto-flagelantes". Em outras palavras, vislumbra-se o processo de naturalização do real.

Neste espectro naturalizante, como fugir de uma pedagogia taylorista-fordista caracterizada por memorizações mecânicas baseadas em estímulos-respostas e de uma pedagogia toyotista da mobilização de diferentes habilidades práticas?

A naturalização se constitui como um instrumento de justificação da ordem social ao apresentá-la como originária da própria "natureza" humana. É a tentativa ideológica de "eternizar" e "universalizar" os aspectos de uma determinada realidade histórica, mostrando-os como desde sempre fossem inerentes à natureza humana.

A tarefa de "eternizar" e "universalizar" as características sociais de uma época ganha força quando a concepção de Ciência circunscreve o campo positivista-empirista, pois nesta visão de Ciência encontram-se os seguintes aspectos:

1. A sociedade é regida por leis naturais, isto é, leis invariáveis, independentes da vontade e ação humanas; na vida social, reina uma harmonia natural.

2. A sociedade pode, portanto, ser epistemologicamente assimilada à natureza (o que classificaremos como "naturalismo positivista") e ser estudada pelos mesmos métodos, démarches e processos empregados pelas ciências da natureza.

3. As ciências da sociedade, assim como as da natureza, devem limitar-se à observação e à explicação causal dos fenômenos, de forma objetiva, neutra, livre de julgamentos de valor ou ideologias, descartando previamente todas as prenoções e preconceitos (Löwy, 1994, p. 17).

Essa concepção de Ciência relaciona-se com a reprodução cultural-econômica, à medida que corrobora para a divulgação de uma visão de desenvolvimento da Ciência e do Mundo baseada num objetivismo "livre de julgamentos de valor ou ideologias" e 


\section{frabalinanecessário \\ issn: 1808-799X \\ ano 7 - número 9 - 2009}

"independentes da vontade e ação humanas", isto é, fundamentais para promover um consenso passivo acerca das contradições sociais presentes na era do capital.

Ao contrário dessa perspectiva, um olhar crítico para a História nos revela que a Ciência se desenvolve e se desenvolveu historicamente devido às "necessidades" sociais estabelecidas em cada momento histórico da civilização. As "questões" e "problemas" de pesquisa estão e estiveram ligadas aos interesses e as necessidades de cada modo de produção social e submetida, como toda prática social, aos interesses de classes ou grupos sociais.

Esse mergulho num ambiente ideológico naturalizante do mundo do trabalho e do cenário de sua precarização foi trazido para a nossa particularidade do Ensino de Ciências e Química e recorrendo aos autores guia da investigação (Gramsci e Apple) apontamos para duas dimensões fundantes das práticas pedagógicas em Química no contexto de jovens e adultos frente aos aspectos hegemônicos explicitados até o momento.

Gramsci e a necessária relação dialética entre Ciência e Vida Social

Diante do cenário mecânico-fordista de sala de aula, percebemos com Gramsci que Ciência e Vida social devem se dialetizar de forma problematizadora. Pedagogicamente, a construção do conhecimento cientifico carece de diálogos sobre saberes e vivências, os quais, intersubjetivamente, medeiam as relações colaborativas entre professor e alunos. A opção pela estratégia da problematização, a partir das contribuições de Delizoicov e Angotti (1990), buscam romper com a conformação pedagógica taylorista-fordista baseada na repetição de frases e conceitos.

Vislumbraram-se, nos primeiros momentos, resquícios de uma pedagogia binária e mecânica do estar certo ou errado, aonde a comprovação do acerto vinha, passivamente, a exteriori, isto é, do "onipotente" professor. $\mathrm{Na}$ fala de um aluno: "nós queremos que o senhor explique as coisas como elas são, e pronto! (Diário de Bordo, 22/09/2005)". 


\section{frabalhonecessário \\ issn: $1808-799 \mathrm{X}$ \\ ano 7 - número 9 - 2009}

Aos poucos, fomos tentando superar o pragmatismo posto e, conseqüentemente, um "certo medo de errar que remete ao silêncio ou a não escrever. Como se eles estivem presos numa lógica de questões $\rightarrow$ respostas certas, o que contraria a própria natureza do processo de construção do conhecimento químico (Diário de Bordo, 31/08/2005)".

Após uma aula, o relato de outro aluno foi logo registrado dessa forma:

Eu entendi professor o que o senhor quer da gente. Quer que a gente raciocine e tente explicar o que a gente tá vendo. Comigo acontece só assim, quando me dizem o nome de alguma peça de algum motor que eu não tivesse visto antes, de nada adianta. Mas se eu trabalho no motor, vejo ele, como ele é, como a peça tá colocada em relação às outras, daí eu consigo memorizar e saber mais tarde, isso por que eu vi e trabalhei com ele. Como o senhor falou, memorizar por memorizar não adianta, a gente esquece rápido (Diário de bordo, 22/08/2005).

A atividade "prática-teórica" muda um pouco o ambiente, ludibria os olhares cansados, suscita expectativas, implica em conversas entre os alunos e afugenta a "imobilidade" corpórea da rotina de sala de aula. Elementos que, ao intencionar tornar os alunos jovens e adultos sujeitos ativos no processo de construção do conhecimento científico, buscam romper com as tradições pedagógicas de base taylorista.

Essa vigilância pedagógica torna-se fulcral se considerarmos a trajetória de alunos jovens e adultos, os quais, na maioria das vezes, retornam à escola depois de longos anos, além de não terem uma relação tão intensa com os meios de propagação cultural ou com a literatura, característica de classes sociais operárias.

O historicismo de Gramsci e a pedagogia do conflito de Apple: contribuições para uma abordagem histórica frente à naturalização da vida social.

Em contraposição as perspectivas naturalizantes do real (desemprego "natural", avanço tecnológico "inevitável", "progresso" científico, etc.), fundamos nossas práticas educativas nas contribuições de Gramsci (1989-a), sendo que, o mesmo, refletindo sobre os processos da ciência, identifica a provisoriedade das "verdades científicas", pois caso essas fossem definitivas, a própria ciência deixaria de existir como tal, resumindo-se a mera repetição do que já foi descoberto, pois o ser humano conhece a realidade somente 


\title{
[trabalhonecessário
}

issn: $1808-799 \mathrm{X}$

ano 7 - número 9 - 2009

em relação ao próprio ser humano, sendo o ser humano um processo histórico, um "devenir", também, a realidade, o conhecimento e a objetividade o são.

Para melhor dizer, sua epistemologia historicista externalista estuda a produção do conhecimento cientifico, por meio das relações entre a ciência e a produção, mediados pela técnica, e a variação dessa relação de acordo com uma determinada formação econômico-social, considerando, também, o objeto e a característica específica da ciência a ser estudada.

Em Apple, no que tange a Teoria Curricular, não é diferente, pois evidencia a conseqüência da ausência dessa abordagem histórica no processo educacional como a criação por parte dos alunos de uma visão "que possui pouca força para questionar a legitimidade das suposições tácitas sobre conflito interpessoal que dirigem suas vidas e suas próprias situações educacionais, econômicas e políticas" [, pois] "não Ihes é mostrado como o debate e o conflito se deram em favor do progresso da ciência (Apple, 1982, p. 140)".

Já em Gramsci, encontramos algumas anotações:

\begin{abstract}
... sabe-se que uma verdade é fecunda somente quando se faz um esforço para conquistá-la; porque de fato ela não existe em si e por si, mas foi conquista do espírito [...] é preciso que em cada mente singular se reproduza aquela ansiedade que tomou o estudioso antes da descoberta [...] Esse representar em ato para os ouvintes a seqüência dos esforços, dos erros e das vitórias pelos quais os homens passaram para alcançar o conhecimento atual é bem mais educativo do que a exposição esquemática desse mesmo conhecimento (Gramsci apud Nosella, 1992, p. 21-22).
\end{abstract}

A atualidade de Gramsci e Apple se explicita ao recorrermos os livros didáticos, com as devidas exceções, praticamente, ocorre um esvaziamento da História das Ciências, onde, comumente, o conhecimento científico é abordado na sua "forma final", por meio de enunciados e fórmulas já "prontas" e pouco se discute acerca de sua gênese.

Ao contrário disso, ressalta Gramsci:

[o aluno] não tem, e não pode ter, um hábito "científico", que só se adquiri com o trabalho especializado: por isso, deve-se ajudá-lo a assimilar pelo menos o "sentido" [significado] deste hábito, através de uma atividade crítica oportuna. Não basta the fornecer conceitos já estabelecidos e fixados em sua expressão "definitiva"; a concreticidade de tais conceitos, que reside no processo que levou 


\section{ftrabalnonecessário \\ issn: $1808-799 \mathrm{X}$ \\ ano 7 - número 9 - 2009}

àquela afirmação, escapa ao [aluno]: deve-se, por isso, lhe oferecer toda a série dos raciocínios e das conexões intermediárias, de um modo bastante determinado e não apenas por indicações (Gramsci, 1978, p. 170).

Posto dessa forma, abordagem histórica intenciona explorar, pedagogicamente, os momentos de ruptura [as "revoluções cientificas (Kuhn, 1997)"] e a descontinuidade do processo evolutivo da ciência, fazer uma historicização dos conceitos, isto é, um breve histórico do seu processo de construção, diferentemente, de como ele é comumente ensinado, em seu fim último e acabado. Isto, também, pressupõe a ruptura com uma postura pedagógica mecanicista, de estímulo-resposta, onde a linguagem e a simbologia química são tomadas em si mesmas.

Essa perspectiva busca explicitar "o fazer ciência" em seus aspectos internos e externos, como uma prática social humana, e os seus produtos, como resultado dessa prática, e entendidos como natureza humanizada. Busca explicitar, também, que nesse processo os seres humanos, ao transformar a natureza, transformam sua própria natureza humana, o mundo e as suas práticas nesse mundo.

O seu engajamento frente à naturalização da vida social se dá, à medida que a manutenção da ordem social exige que se divulgue a idéia de não ruptura, uma vez que, se vivenciada no devir da Ciência poderia ser identificada analogamente no processo histórico mais amplo. Tal manutenção intenciona impedir a formação do autoconhecimento acerca do processo histórico da construção do conhecimento vinculado à totalidade social, o papel da ciência na construção das condições materiais da existência humana, imersa em contradições históricas, culturais, ideológicas e políticas.

\section{Dos encaminhamentos curriculares}

Com base nas reflexões acerca do mundo do trabalho e suas relações com o processo de construção curricular, mediadas pelo pensamento de Antonio Gramsci e Michael Apple, inferimos que a assunção da "formação de competências e habilidades" como princípio organizativo, tem se materializado "na prática", como determinante para 


\section{frabalhonecessário \\ issn: $1808-799 \mathrm{X}$ \\ ano 7 - número 9 - 2009}

uma abordagem "psicologizada" do currículo, isto é, esvazia as discussões mais amplas sobre os problemas tomados como "geradores" da construção curricular.

Essa abordagem psicologizada se mostrou anacrônica em relação ao próprio funcionamento do capitalismo contemporâneo, uma vez que o funcionamento e o desenvolvimento do mesmo implicam na imposição de num limite estrutural, que impede a manutenção objetiva da geração de empregos, pois conseguiu "sobreviver" com os elevados índices de desemprego atuais. Pois, quando encaramos o desemprego a partir desses aspectos econômicos, vemos que as questões acerca da necessidade de qualificação profissional tendem a mascarar-legitimar este limite estrutural próprio da organização social capitalista, ao apresentá-lo como sendo um limite exclusivamente cultural.

Se por um lado, a formação de competências e habilidades pode servir como tranqüilizante ideológico, ao alimentar a idéia de que a escolaridade resulta em empregabilidade, por outro, a escola, ao contribuir para a formação de indivíduos multitarefistas, estaria livrando o capitalista da responsabilidade de custear a qualificação da força de trabalho, pois a mesma estaria sendo realizada com o dinheiro público, fruto de parte da mais-valia total produzida pela sociedade (dos impostos recolhidos pelo Estado).

Dessa forma, podemos dizer que no processo de elaboração curricular, a ênfase na formação de competências e habilidades atuou como dispositivo de hegemonia à medida que corroborou para a naturalização das contradições encontradas no mundo do trabalho, como por exemplo, na questão do desemprego, quando esse "dispositivo", centralizado na formação de competências, fechou as portas para as discussões acerca dos aspectos ideológicos e conjunturais (sócio-econômicos) nos quais a Educação está imersa, dessa forma, se não são "discutidos", dificilmente seriam incorporados como aspectos relevantes nas atividades curriculares.

Assim, esses são os nossos desafios, isto é, os de problematizar o ambiente ideológico no qual a Educação de Jovens e Adultos está imersa e intencionar, pedagogicamente, a abordagem do processo de historicização os saberes escolares e 


\section{frabalhonecessário \\ issn: 1808-799X \\ ano 7 - número 9 - 2009}

seus processos de forma que estejam, organicamente, ligados às práticas cotidianas dos alunos, no intuito de fornecer-lhes elementos para que rompam com o senso comum (estático, ideologicamente neutro) e construam autonomamente concepções de mundo unitárias e coerentes (conscientes da provisoriedade e do aspecto conflituoso da realidade), à medida que se contraponham às concepções "naturalizantes" da vida social, legitimadoras de posturas auto-flagelantes, pragmáticas e individualistas recorrentes na era do capitalismo tardio.

Alceu Júnior Paz da Silva (Químico Licenciado, Mestre em Educação pela UFSM, Professor do Instituto de Ciências Naturais, Humanas e Sociais, da Universidade Federal de Mato Grosso, Sinop/MT).

Luiz Carlos Nascimento da Rosa (Químico Licenciado, Mestre em Educação pela UFSC, Professor no Departamento de Metodologia do Ensino do Centro de Educação da Universidade Federal de Santa Maria, Santa Maria/RS).

\section{Bibliografia consultada:}

APPLE, M. 1982. Ideologia e currículo. São Paulo: Brasiliense.

APPLE, M. 1989. Educação e poder. Porto Alegre: Artes Médicas.

BRASIL. Ministério da Educação. 2002. Secretaria de Educação Fundamental Proposta Curricular para a educação de jovens e adultos: segundo segmento do ensino fundamental: $5 a$ a $8 a$ série: introdução v. 1, Secretaria de Educação Fundamental.

DELIZOICOV, D.; ANGOTTI, J. A. 1990. Metodologia do ensino de ciências São Paulo: Cortez.

DUARTE, N. 2001. Vigotski e o aprender a aprender: críticas às apropriações neoliberais e pós-modernas da teoria vigotskiana. $2^{\mathrm{a}}$ ed. Campinas: A. Associados.

GENTILI, P. 2002. Três teses sobre a relação trabalho e educação em tempos neoliberais in: LOMBARDI, J. C., SAVIANI, D. e SANFELICE, J. L. (orgs.) Capitalismo, trabalho e educação Campinas: A. Associados

GRAMSCI, A. 1989-a. Concepção dialética da história. Rio de Janeiro: C. Brasileira GRAMSCI, A. 1978. Os intelectuais e a organização da cultura. Rio de Janeiro: C. Brasileira.

GRAMSCI, A. 1989-b. Maquiavel, a política e o estado moderno. $7^{\text {a }}$ ed. Rio de Janeiro: C. Brasileira.

GRUPPI, L. 1986.Tudo começou com Maquiavel: as concepções de Estado em Marx, Engels, Lênin e Gramsci $7^{\text {a }}$ ed. Porto Alegre: L\&PM.

KUENZER, A. Z. 2002. Exclusão includente e inclusão excludente: a nova forma de dualidade estrutural que objetiva as novas relações entre trabalho e educação in: 


\section{frabalhonecessário \\ issn: $1808-799 \mathrm{X}$ \\ ano 7 - número 9 - 2009}

LOMBARDI, J. C., SAVIANI, D. e SANFELICE, J. L. (orgs.) Capitalismo, trabalho e educação Campinas: A. Associados.

LUCENA, C. 2005. Marxismo, crise do capitalismo monopolista e qualificação dos trabalhadores in: LOMBARDI, J. C. e SAVIANI, D. (orgs.) Marxismo e educação: debates contemporâneos Campinas: A. Associados.

KUHN, T. S. 1997. A Estrutura das Revoluções Científicas. $5^{\mathrm{a}}$ ed. São Paulo: Perspectiva.

LÖWY, M. 1994. As aventuras de Karl Marx contra o Barão de Münchhausen: marxismo e positivismo na sociologia do conhecimento. $5^{\text {a }}$ ed. São Paulo: Cortez.

MANDEL, E. 1982. O capitalismo tardio São Paulo: A. Cultural.

MARX, K. 2004-a. O Capital: crítica da economia política Livro I vol.1 $22^{a}$ ed. Rio de Janeiro: C. Brasileira.

MARX, K. 2004-b. O Capital: crítica da economia política Livro I vol $222^{a}$ ed. Rio de Janeiro: C. Brasileira.

MELO, D. 2006-a. Quais são suas competências?... Zero Hora, Porto Alegre, 03 dez. 2006-a. Caderno Empregos e Oportunidades, p.3.

MELO, D. 2006-b. Conflitos no escritório... Zero Hora, Porto Alegre, 26 nov. Caderno Empregos e Oportunidades, p.3.

NOSELLA P. 1992. A escola de Gramsci Porto Alegre: A. Médicas.

NOSELLA P. 2004. A escola de Gramsci $3^{a}$ ed. rev. e atual. São Paulo: Cortes.

PORTELLI, H. 2002. Gramsci e o bloco histórico Rio de Janeiro: Paz e Terra.

PRIEB, S. 2005. O trabalho à beira do abismo: uma crítica marxista à tese do fim da centralidade do trabalho ljuí: Unijuí.

ROSA, L. C. N. da; BERNI, C. P.; SOUZA, M.; SILVA, A. J. P. da; FLORES, G. da S. 2004. Tópicos sobre epistemologia: buscando o bom senso através de Gramsci. in: Utopía y Práxis Latinoamericana: Revista Internacional de Filosofia Iberoamericana y Teoria Social. Año $9 n^{\circ}$ 26. Maracaibo: Universidad del Zulia, p. 91-103.

ROSA, L. C. N. DA; SILVA, A. J. P. DA; SILVA, F. G. DA E COSTA, N. M. Epistemologia e História da Química: fundamentos para a prática educativa artigo submetido à Revista de Educação Pública, publicação do Programa de Pós-Graduação em Educação da Universidade Federal de Mato Grosso, 2009.

RUBINSTEIN, S. 1963. El ser y la conciencia Montevideo: Pablo del Rio.

SANTI, A. 2006. de. Ler faz diferença no mercado de trabalho... Zero Hora, Porto Alegre, 05 nov. Caderno Empregos e Oportunidades, p.3.

VIGOTSKI, L. S. 1996. Pensamento e linguagem. São Paulo: Martins Fontes. 